\title{
Gravitational Search and Harmony Search Algorithms for Solving the Chemical Kinetics Optimization Problems
}

\author{
Leniza V. Enikeeva ${ }^{1,2, a^{*}}$, Elena N. Shvareva ${ }^{2, b}$, and Irek M. Gubaydullin ${ }^{2,3, c}$ \\ 1 Novosibirsk State University, Novosibirsk, Russia \\ 2 Ufa State Petroleum Technological University, Ufa, Russia \\ 3 Institute of Petrochemistry and Catalysis - Subdivision of the Ufa Federal Research Centre of RAS, Ufa, \\ Russia \\ E-mail: aleniza.enikeeva@gmail.com (Corresponding author), belenaniks@yandex.ru, cirekmars@mail.ru
}

\begin{abstract}
The article is dedicated to the analysis of the global optimization algorithms application to the solution of inverse problems of chemical kinetics. Two heuristic algorithms are considered - the gravitational search algorithm and the harmony algorithm. The article describes the algorithms, as well as the application of these algorithms to the optimization of test functions. After that, these algorithms are used to search for the kinetic parameters of two chemical processes - propane pre-reforming on $\mathrm{Ni}$-catalyst and catalytic isomerization of pentane-hexane fraction. For the first process both algorithms showed approximately the same solution, while for the second problem the gravitational search algorithm showed a smaller value of the minimizing function. Wherefore, it is concluded that on large-scale problems it is better to use the gravitational search algorithm rather than the harmony algorithm, while obtaining a smaller value of the minimizing function in a minimum time. On low-scale problems both algorithms showed approximately the same result, while demonstrating the coincidence of the calculated data with the experimental ones.
\end{abstract}

Keywords: Mathematical modeling, inverse problem of chemical kinetics, gravitational search algorithm, harmony search algorithm.

ENGINEERING JOURNAL Volume 25 Issue 6

Received 30 December 2020

Accepted 5 June 2021

Published 30 June 2021

Online at https://engj.org/

DOI:10.4186/ej.2021.25.6.107 


\section{Introduction}

Optimization problems can be found in almost all fields of technology. Optimization in general is the process of maximizing beneficial characteristics, ratios and minimizing costs. Optimization problems are usually very complex and have many conditions. The development of optimization methods is very important for engineering applications. Most traditional optimization methods require gradient information and therefore cannot be used to solve non-differentiable functions. Furthermore, such methods usually suffer from falling into the local optimum trap when solving complex optimization problems with many local optima. However, many real engineering optimization problems are very complex and their objective functions usually have several local optima. The disadvantages of traditional optimization methods have prompted researchers to develop better optimization methods for solving real engineering optimization problems in particular heuristic optimization methods [1].

Heuristic optimization methods have found widespread use in solving engineering optimization problems in various fields, such as robot path planning [2], navigation of unmanned aerial vehicles [3], identification of influential users in the social network [4], and others.

However, today a fairly small number of articles are dedicated to the application of modern metaheuristic methods to the problems of modeling industrial chemical processes. The first stage of modeling a reactor of an industrially important chemical process - building a kinetic model - involves solving the inverse problem of chemical kinetics, which in turn is a laborious optimization problem. The inverse problem of chemical kinetics is reduced to continuous global optimization problems. The features of such problems are often nonlinearity, non-differentiability, multi-extremality (multimodality), ravines, lack of analytical expression and high computational complexity of the optimizable functions, as well as large-scale of the search space. These features of the chemical kinetics problems explain the absence of a universal algorithm for their solution. In the general case, the kinetic parameters of the reaction, a set of values of the activation energies and preexponential parameters, act as optimization parameters. Most industrial chemical processes are complex chemical reactions, in other words, they include more than one stage, but sometimes dozens of stages. The kinetic parameters are searched for each stage. This means that inverse problems of chemical kinetics are optimization large-scale problems. The convergence of heuristic algorithms to the global solution has not been proven, but it has been experimentally established that in most cases they give a fairly good solution. Heuristic search optimization algorithms in comparison with classical algorithms have advantages; first of all, when solving the large-scale problems, multimodal and poorly formalized problems, such as inverse problems of chemical kinetics.
Thus, the solution of inverse problems of chemical kinetics by modern heuristic methods is an urgent problem.

The objects of study in this article are two catalytic processes:

- catalytic isomerization of pentane-hexane fraction;

- pre-reforming of hydrocarbons into synthesis gas with a high methane content.

So far, the process of catalytic isomerization of pentane-hexane fraction is becoming widespread in the oil refining industry due to the fact that this process is aimed at converting linear alkanes with low octane rating into their branched structure isomers with a higheroctane rating. At the same time, the content of aromatic hydrocarbons in the process products is practically absent. In the oil refining industry arises the problem of increasing the efficiency of the isomerization process, which is associated with the modernization of reactor equipment and the optimization of operating parameters for installations, an important component of which is the development of algorithmic and problem-oriented software.

Steam-reforming of hydrocarbons is widely used in the modern chemical industry to obtain synthesis gas for the synthesis of methanol and hydrogen for the synthesis of ammonia and hydrogenation processes in petrochemistry and oil refining. For oil refineries, steamreforming of mixtures with a high content of $\mathrm{C}_{2}+$ hydrocarbons, including olefins, (so-called refinery gases) is especially relevant. For processing gases such composition proposed two-stage scheme for producing synthesis gas from the pre-reforming of heavy hydrocarbons in the gas mixture with a high content of methane at $450-500{ }^{\circ} \mathrm{C}$ followed by conversion to synthesis gas at higher temperatures. While steamreforming of methane over nickel catalysts is well studied, for pre-reforming on $\mathrm{Ni} / \mathrm{MgAl}_{2} \mathrm{O}_{4}$ and $\mathrm{Rh}$-containing catalysts, the kinetics of steam-reforming reactions, especially olefins, is not well studied.

Therefore, the purpose of this article is to develop a software package "System for the optimization and investigation of industrially important heterogeneous catalytic processes" for solving inverse problems in modeling the catalytic isomerization reaction of pentanehexane fraction and the process of pre-reforming of hydrocarbons using modern heuristic optimization methods. The gravitational search method and the harmonic search method are selected as heuristic methods.

\section{Related Works}

In recent years, some metaheuristic optimization algorithms, such as Particle Swarm Optimization [5, 6], Genetic Algorithms [7, 8], have been applied to solve chemical kinetics problems.

Kazantsev at al. [5] used particle swarm optimization (PSO) method for solving the inverse chemical kinetics problem for the $\mathrm{n}$-hexane isomerization process on a 
sulfated zirconia catalyst sample. Pontes at al. applied the heuristic method of particle swarm optimization for inverse problem analysis during the identification of reaction kinetics constants in microreactors for biodiesel synthesis [6].

In [9] the inverse mathematical problem of estimating the parameters of a system of differential equations and its initial point using the measured data was provided for the hexadecane disintegration reaction. A specific heterogeneous multi-objective genetic algorithm with the island meta-heuristic was used and its efficiency in solving this problem was proved by the investigation results.

Alireza Taghipour et. al. [10] developed a discrete six-lump kinetic model for the thermal cracking of vacuum residue in the visbreaking process, and the timedependent behavior of each individual lump has been determined. A combination of the heuristic method and gradient-based method (hybrid method) has been taken into account to optimize the parameters of the model. A number of 60 parameters was considered primarily, which has been reduced to 36 with the aim of flash calculation information, and optimized.

In [11] the reaction in the human stomach when neutralizing acid with an antacid tablet was simulated and the evolution over time of the concentration of all chemical species present in the reaction medium was obtained. Kinetic constants of a chemical reaction in heterogeneous phase have been determined and improved by using hyperheuristics based on parameterized schemes for metaheuristics. The hyperheuristic approach provided satisfactory values for the metaheuristic parameters and, consequently, satisfactory metaheuristics for the problem of determining the kinetic constants.

In Ref. [12], the process parameters were identified and optimized by gravitational search algorithm (GSA) for the production of synthesis gas (Synthesis gas is employed in chemical processes for the production of methanol, ammonia, hydrogen and higher hydrocarbons).

In work [13] the harmonic algorithm was used to improve the Alopex-based evolutionary algorithm for application in reaction kinetic parameter estimation. Harmony search Alopex-based evolutionary algorithm was used to estimate reaction kinetic parameters for a heavy oil thermal cracking three lumps model and Homogeneous mercury $(\mathrm{Hg})$ oxidation.

The literature review proved that various heuristic methods have already been used to solve problems of chemical kinetics, but there are practically no references to the works devoted to the application of the method of gravitational and harmonic search to the development of kinetic models of chemical reactions. However, these algorithms are successfully used to solve optimization problems in various fields of science and technology.

The gravity search algorithm is widely used in Power engineering. Bhattacharya et al. [14] solved the multiobjective optimal power flow problem using GSA. The objectives of this study were fuel cost, loss, and voltage deviation. Jahan et al. [15] solved the security constrained optimal power flow problem by employing an enhanced GSA. Duman et al. [16] applied GSA to find the best settings for control variables of the optimal power flow problem. Sarker et al. [17] applied GSA to solve OPF problem in the presence of multiple Unified Power Flow Controller (UPFC) devices. In this study GSA was utilized to find the optimal number and location of UPFC devices to minimize the generation cost and power system losses. Shaw et al. [18] applied an opposition-based GSA for optimizing the reactive power dispatch by finding the optimal settings of the control variables for the power system. Mondal et al. [19] used GSA in the economic emission load dispatch problem to minimize the emission of nitrogen oxides and fuel cost. Niknam et al. [20] utilized multi-objective GSA for optimal reactive power dispatch and voltage control to improve transmission loss and voltage stability. Jiang et al. [21] proposed a hybrid PSO and GSA to solve economic emission load dispatch problems considering various practical constraints.

Heuristic algorithms are useful tools to refine image processing procedures by selecting salient features, and tuning the algorithm parameters. Chakraborti et al. [22] selected features for face recognition problems using modified version of GSA in which the employed features are local binary pattern, modified census transform, and local gradient pattern. An image segmentation method based on neural networks was produced in Ref. [23], in which the weights and biases of the neural network were optimized by GSA to minimize the error rate. Authors in [24] give a recent comprehensive survey on GSA.

As for the harmonic search algorithm, it has also found application in a variety of scientific and engineering tasks.

Jaeyoung Park et al. [25] developed cascaded improved harmony search (CIHS) based on harmony search. And as a practical application, the line impedance estimation problem for a general radial power system was formulated, to which CIHS was applied. Paper [26] presents a new optimization technique developed based on harmony search algorithm (HSA), called chaotic improved harmony search algorithm (CIHSA). To validate the effectiveness of CIHSA, it was used to solve the combined economic emission dispatch problem, which practically is a complex high-dimensional nonconvex optimization task with several equality and inequality constraints.

However, there is still no persistent conclusion to select a certain algorithm to solve inverse problems of chemical kinetics. Next, we proceed to the mathematical description of inverse problems of chemical kinetics.

\section{Mathematical Model}

\subsection{Propane Pre-reforming into Methane-rich Gas over Ni Catalyst}


The first process under study is propane prereforming into methane-rich gas over Ni catalyst, which is an industrially important chemical process [27]. Prereforming of propane was studied over industrial nickelchromium catalyst at pressure of 1 and 5 bar, low steam to carbon molar ratio of 1 ratio, in the temperature range of $220-380{ }^{\circ} \mathrm{C}$ and at flow rates of 4000 and $12000 \mathrm{~h}^{-1}$. The reaction scheme consists of two reactions: propane steam conversion and $\mathrm{CO}_{2}$ methanation $[28,29]$ :

$$
\begin{gathered}
\mathrm{C}_{3} \mathrm{H}_{8}+6 \mathrm{H}_{2} \mathrm{O} \rightarrow 10 \mathrm{H}_{2}+3 \mathrm{CO}_{2} \\
\mathrm{CO}_{2}+4 \mathrm{H}_{2} \rightleftarrows \mathrm{CH}_{4}+2 \mathrm{H}_{2} \mathrm{O}
\end{gathered}
$$

The reaction rates (1) - (2) are expressed according to the Langmuir-Hinshelwood model:

$$
\begin{gathered}
W_{r e f}=\frac{k_{r e f} \cdot \exp \left(-\frac{E_{r e f}}{R T}\right) \cdot C_{\mathrm{C} 3 \mathrm{H} 8}}{\left(1+B \cdot C_{\mathrm{C} 3 \mathrm{H} 8}\right)^{m}}, \\
W_{\text {met }}=k_{\text {met }} \cdot \exp \left(-\frac{E_{\text {met }}}{R T}\right) \cdot C_{\mathrm{H} 2} \cdot\left[1-\frac{P_{\mathrm{CH} 4} P_{\mathrm{H} 2 \mathrm{O}}^{2}}{K_{e q} P_{\mathrm{CO} 2} P_{\mathrm{H} 2}^{4}}\right],
\end{gathered}
$$

where $W_{r e f}$ and $W_{m e t}$ are the reaction rates; $E_{r e}$ and $E_{m e t}$ are the observed activation energies, $\mathrm{J} / \mathrm{mol} ; k_{\text {rff }}$ and $k_{\text {met }}$ are the pre-exponential multipliers; $B$ is the constant parameter, $T$ is the temperature, $\mathrm{K} ; \mathrm{R}$ is the universal gas constant, $\mathrm{J} \cdot(\mathrm{K} \cdot \mathrm{mol})$. The "ref" and "mel" indexes refer to pre-reforming and methanation reactions, respectively. $C_{\mathrm{C} 3 \mathrm{H} 8}$ and $C_{\mathrm{H} 2}$ are concentrations of propane and hydrogen, $\mathrm{mol} / \mathrm{m}^{3} ; m$ is order of the denominator, which varied from 0 to $2 ; K_{e q}$ is the equilibrium constant of $\mathrm{CO}_{2}$ methanation; $P_{\mathrm{CH} 4}, P_{\mathrm{H} 2 \mathrm{O}}, P_{\mathrm{CO} 2}, P_{\mathrm{H} 2}$ are partial pressures of the corresponding substances, bar. The mathematical model is a system of equations of material balance:

$$
\left\{\begin{array}{l}
G \frac{d y_{i}}{d l}=\left(v_{i}^{r e f} W_{r e f}+v_{i}^{m e t} W_{m e t}\right) m_{i} \\
0 \leq l \leq L, i \in\left\{\mathrm{C}_{3} \mathrm{H}_{8}, \mathrm{CH}_{4}, \mathrm{H}_{2} \mathrm{O}, \mathrm{H}_{2}, \mathrm{CO}_{2}\right\} \\
l=0, y_{i}=y_{i 0},
\end{array}\right.
$$

where $G$ is a mass flow of the mixture, $\mathrm{kg} /\left(\mathrm{m}^{2} \cdot \mathrm{sec}\right) ; y_{i}$ is a mass fraction of the $i$-th component; $v_{i}$ is a stoichiometric coefficient of the $i$-th component; $m_{i}$ is a molar mass of the $i$-th component, $\mathrm{kg} / \mathrm{mol} ; l$ is coordinate along the catalytic layer, $\mathrm{m}$; $L$ is a length of the catalytic layer, $\mathrm{m}$. The mathematical model of chemical kinetics problems is a system of differential equations that describes the variations in substance concentrations over time according to the rates of reaction stages. The system of differential equations is a Cauchy problem containing the initial data [30-32]. The numerical solving of such a system of equations is a direct problem of chemical kinetics. Determining the kinetic parameters of reaction stages by comparing calculated values of substance concentrations and experimental results is an inverse problem of chemical kinetics. The mathematical problem is to minimize the functional of the deviation between calculated and experimental values. The functional of minimizations determined as the sum of absolute deviations between calculated and experimental concentrations:

$$
f=\sum_{i=1}^{M} \sum_{j=1}^{N}\left|x_{i j}^{\text {calc }}-x_{i j}^{\text {exp }}\right| \rightarrow \min
$$

where $x_{i j}^{\text {calc }}$ and $x_{i j}^{e x p}$ are calculated and experimental values of component concentrations; $M$ is the number of measuring points; $N$ is the number of substances involved in the reaction.

\subsection{Catalytic Isomerization of the Pentane-Hexane Fraction}

The object of this research is the process of catalytic isomerization of the pentane-hexane fraction, for this process is the most dynamically developing. The catalytic isomerization is applied to increase the petrol octane number via structural changing of a carbon skeleton of linear paraffin. Hydroprocessed petrol fractions $62-70{ }^{\circ} \mathrm{C}$, raffinates of catalytic reforming, etc. are used as a raw material. The process takes place in hydrogen in presence of bifunctional catalysts [33].

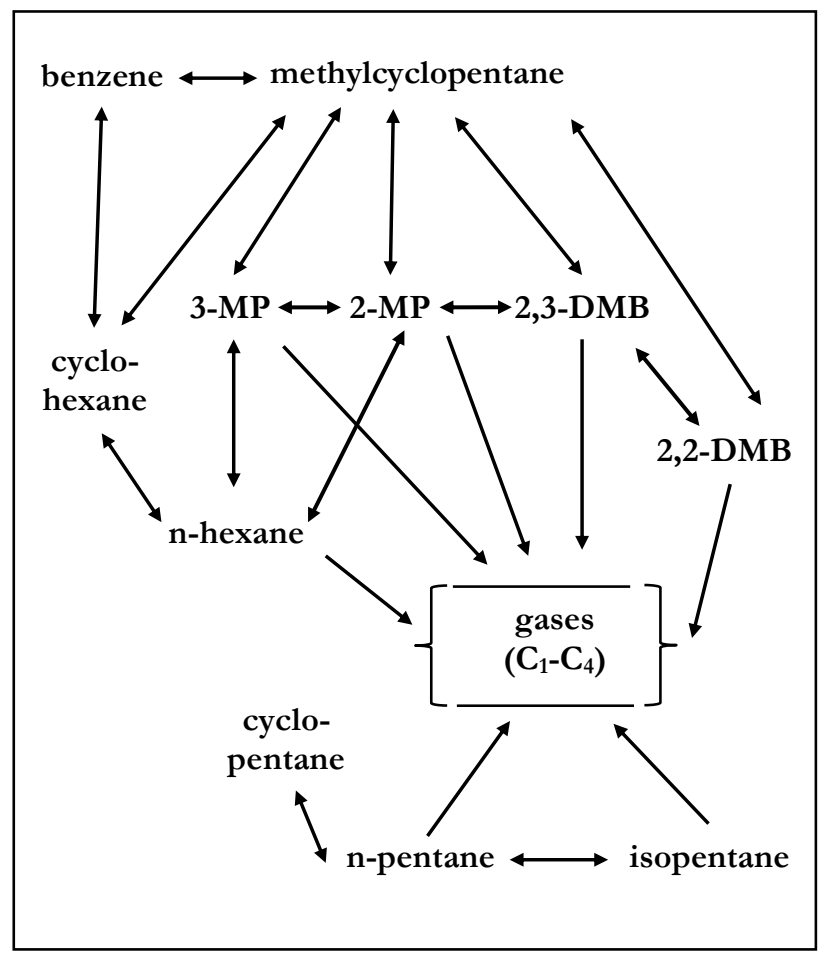

Fig. 1. Transformations of the catalytic isomerization of the pentane-hexane fraction (MP - methyl pentane; DMB — dimethyl butane).

The reaction rates included in the kinetic model were recorded according to the mass action law. Mathematical 
model of the process represents a system of non-linear differential equations [34-36]:

$$
\begin{gathered}
\frac{d x}{d \tau}=\sum_{i=1}^{J} v_{i j} w_{j}, i=1, \ldots, I, \\
w_{j}=k_{j} \prod_{i=1}^{J}\left(\frac{x_{i}}{F}\right), \\
k_{j}=k_{j}^{0} \exp \left(-\frac{E_{j}}{R T}\right)
\end{gathered}
$$

with initial conditions: at $\tau=0, x_{i}(0)=x_{i}^{0}$,

where $v_{i j}$ are stereochemical indexes of chemical transformation schemes; $J$ is the number of stages, $x_{i}$ are mole discharges of the $i$-th component involved in reactions, $\mathrm{kmol} / \mathrm{h} ; I$ is the number of components; $w_{j}$ is the rate of the $j$-th stage, $\mathrm{kmol} /\left(\mathrm{h} \cdot \mathrm{kg}\right.$ cat.); $E_{j}$ are reactions activation energies, $\mathrm{J} / \mathrm{mol} ; \mathrm{R}$ is gas constant, $\mathrm{R}=8.31 \mathrm{~J} /(\mathrm{mol} \cdot \mathrm{K}) ; \mathrm{T}$ is temperature, $\mathrm{K} ; k_{j}^{0}$ are preexponential factors, $\mathrm{kmol} /(\mathrm{h} \cdot \mathrm{kg}$ cat.); $\tau$ is conditioned contact time, (kg cat.); $\mathrm{F}$ is mole discharge of the flow, $\mathrm{kmol} / \mathrm{h}$.

Mathematical model (7) represents the Cauchy task that accounts the raw material flow speed in the reactor and temperature change (8) because it is necessary to account non-isothermal character of the technological process:

$$
\begin{gathered}
\frac{d T}{d \tau}=\frac{\sum_{i=1}^{I}\left(\frac{d x_{i}}{d \tau} \cdot \Delta H_{T_{i}}^{f}\right)}{\sum_{i=1}^{J}\left(x_{i} C_{p_{i}}^{T}\right)}, \\
\frac{d F}{d \tau}=\sum_{i=1}^{I} \frac{d x_{i}}{d \tau}
\end{gathered}
$$

with initial conditions: at $\tau=0, T(0)=T^{0}$,

where $\mathrm{T}$ is temperature, $\mathrm{K}, \Delta H_{T i}^{f}$ is enthalpy of the $i$-th component formation at temperature $\mathrm{T}, \mathrm{J} / \mathrm{mol} ; C_{p i}^{T}$ is specific heat of the $i$-th component at temperature $T$, $\mathrm{J} / \mathrm{mol} \cdot \mathrm{K}) ; F$ is mole discharge of the flow, $\mathrm{kmol} / \mathrm{h}$.

Therefore, the elaborated mathematical model represents a system of 19 equations (17 equations for individual components, one for temperature, and one for mole discharge of the raw material in the reactor). The solution of systems of differential equations (5) and (7) (8) is a direct problem of chemical kinetics, as a result of which, for given kinetic parameters, the change in the concentrations of the reaction components is calculated. In this paper, as a solver of systems of differential equations, we used the 'Radau' option of the 'solve_ivp' method of the scipy library in the Python programming language. Implicit Runge-Kutta method of the Radau IIA family of order 5 [37] with a third-order accurate embedded formula.
Contrariwise, the inverse problem is the search for optimal kinetic parameters - activation energies $E_{j}$ and pre-exponential factors $k_{j}^{0}$, included in Eq. (7). The total number of unknown parameters is 96 (48 activation energies and 48 pre-exponential multipliers).

The search for kinetic parameters for the problems presented in paragraphs 2.1 and 2.2 is the inverse problem of chemical kinetics. In this paper, two heuristic algorithms are proposed to be applied to solve these problems.

\section{The Framework of Proposed Algorithm}

In this section, the algorithms used in this paper are briefly introduced. We consider gravitational search algorithm (GSA) and harmony search algorithm (HSA) for solving the inverse problems of chemical kinetics. GSA and HSA have been recently developed and found to be comparatively efficient. These algorithms are nature inspired, and population based. A brief description of the algorithms and pseudocodes will be given.

\subsection{Gravitational Search Algorithm (GSA)}

In this algorithm, search agents are objects, and the best ones have a large mass. Objects are attracted to each other by the force of gravity. Agents with a large mass attract lighter ones. Each object represents a solution to the problem and has its own position, inertial mass, passive and active gravitational masses. The heaviest agent is the current best solution, and other agents are attracted by this agent. The GSA applies Newtonian laws of gravity and motion. Each object attracts each other, and the gravitational force between two objects is proportional to the product of their masses and inversely proportional to the distance between them, page 2, write down the subscripts in substances $R$. That is in an environment with $N$ objects the position of object $i$ is equal to:

$$
X_{i}=X_{i}^{1}, \ldots, X_{i}^{d}, \ldots, X_{i}^{n}, \text { for } i=1,2, \ldots, N,
$$

where $X_{i}^{d}$ is the position of object $i$ in the $d^{\text {th }}$ dimension. The force applied to object " $i$ " from agent " $j$ " at time $t$ is:

$$
F_{i j}^{d}(t)=G(t) \frac{M_{p t}(t) M_{a j}(t)}{R_{a j}(t)+\varepsilon}\left(X_{j}^{d}(t)-X_{i}^{d}(t)\right)
$$

where $M_{a j}$ is the gravitational mass applied to agent $j, M_{p i}$ is the passive gravitational mass applied to agent $i, G(t)$ is gravitational at time $t, \varepsilon$ is a small constant, and $R_{i j}(t)$ is the Euclidian distance between objects $i(i=1,2, \ldots, N)$ and $j(j=1,2, \ldots, N)$ :

$$
R_{i j}(t)=\left\|X_{i}(t), X_{j}(t)\right\|_{2} .
$$


The total force that is applied to object $i$ in $d$ is a random sum of $d^{\text {th }}$ components of the forces from other objects:

$$
F_{i}^{d}(t)=\sum_{j=1, j \neq i}^{N} \operatorname{rand}_{j} F_{i j}^{d}(t)
$$

where rand $_{j}$ is a number in $[0,1]$. The acceleration of the object $i$ at time $t$, and in direction $d^{t h}, a_{i}^{d}(t)$ is given as:

$$
a_{i}^{d}(t)=\frac{F_{i j}^{d}(t)}{M_{i i}^{d}(t)},
$$

where $M_{i i}$ is the inertial mass of object $i$. The new velocity of an object is a fraction of its current velocity and its acceleration. Its position and velocity are calculates as follows:

$$
\begin{aligned}
& v_{i}^{d}(t+1)=\operatorname{rand}_{i} v_{i}^{d}(t)+a_{i}^{d}(t), \\
& x_{i}^{d}(t+1)=x_{i}^{d}(t)+v_{i}^{d}(t+1),
\end{aligned}
$$

where rand $_{i}$ is a uniform variable in $[0,1]$. The constant, $G$, is initialized and reduced with time to control the accuracy of the search:

$$
G(t)=G\left(G_{0}, t\right)
$$

The following expression was used as a function of Eq. (10):

$$
G=G_{0} \exp \left(-\frac{\alpha t}{z}\right)
$$

where $z$ is the number of iterations.

The gravitational and inertial masses are updated by the equations given below:

$$
\begin{gathered}
M_{a i}=M_{p i}=M_{i i}=M_{i} ; i=1,2, \ldots, N ; \\
m_{i}(t)=\frac{\operatorname{fit}_{i}(t)-\operatorname{worst}(t)}{\operatorname{best}(t)-\operatorname{worst}(t)}, M_{i}(t)=\frac{m_{i}(t)}{\sum_{j=1}^{N} m_{j}(t)}
\end{gathered}
$$

where $f_{i}(t)$ represents the fitness value of the agent $i$ at time $t$, and, worst(t) and best(t) are defined as follows (for a minimization problem):

$$
\operatorname{best}(t)=\min _{j \in\{1, \ldots, N\}} \text { fit }(t), \text { worst }(t)=\max _{j \in\{1, \ldots, N\}} \text { fit }(t) \text {. }
$$

The GSA pseudocode is shown in Table 1 [38]. We developed a program in the Python 3 programming language, based on the code repository available at the link https://github.com/himanshuRepo/GravitationalSearch-Algorithm (open access).
Table 1. Pseudocode of Gravitational Search Algorithm.

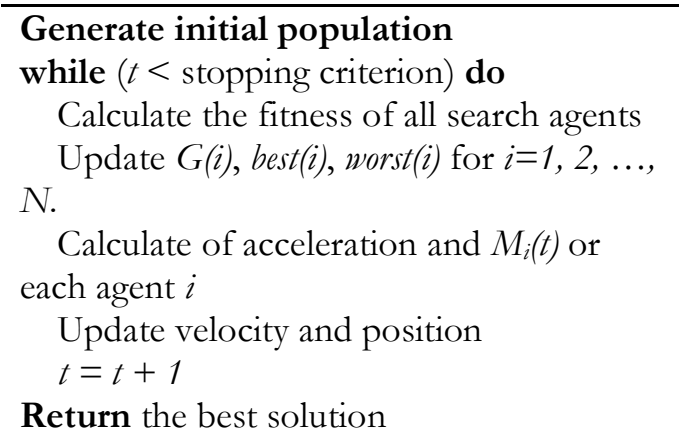

The communication of agents is provided through gravitational force. The exploitation for the GSA is guaranteed by heavy masses that move slowly. In order to provide a balance between exploration and exploitation, the number of agents with a lapse of time in Eq. (9) should be reduced. To avoid getting into local optima the GSA uses exploration at initial phases. The level of exploration should be decreased and exploitation should be increased throughout the iterations. In order to improve the efficiency of GSA, the $K_{\text {best }}$ agents should attract the others and thus, $K_{\text {best }}$ is a function that changes with time. It is initially set to $K_{0}$ at the beginning and modified in a monotonically decreasing fashion. Equation (9) is formalized as:

$$
F_{i}^{d}(t)=\sum_{j \in K_{\text {best }}, j \neq i}^{N} \operatorname{rand}_{j} F_{i j}^{d}(t),
$$

where $K_{\text {best }}$ is the set of heaviest $K$ objects with the best fitness value and the largest mass.

\subsection{Harmony Search Algorithm (HSA)}

Harmony search is a popular universal algorithm that is used for global optimization. HSA is a metaheuristic algorithm based on musical compositions and the process of writing a composition [39]. HS is proposed in 2001 and has been applied to numerous optimization problems. In HS, a musician has three possible choices when improvising a song: (1) playing any well-known piece of music (pitches in harmony) naturally from memory; (2) playing music similar to an existing piece (by adjusting the pitch); or (3) composing random harmonic notes [40]. We assign the individuals $s_{i}$ to the musicians, and the population $S=\left\{s_{i}, i \in[1:|S|]\right\}$ to the orchestra. To the chord that the musician takes $s_{i}$ at a given time, we compare the value of the vector of variable parameters $X_{i}$. The set of current coordinates $X_{i}, \mathrm{i} \in$ $[1:|S|]$ forms the $(|S| \mathrm{x}|X|)$ harmony memory matrix $H^{M}$. The harmony memory ensures to keep the best harmonies to new harmony memory. It is assigned as a parameter, $r_{\text {accept }}$ that is called harmony memory accepting rate. Usually, this parameter is taken in the range [0.7, 0.95]. 
The pitch adjustment is the second parameter determined by the bandwidth (brange) and the adjusting rate of a pitch $r_{p a}$. Pitch adjustment strategy is organized as

$$
x_{\text {new }}=x_{\text {old }}+b_{\text {range }} \cdot \varepsilon
$$

where $x_{\text {old }}$ is the current pitch, and $x_{\text {new }}$ is the new solution after the adjustment of pitch. This process generates a neighboring solution to the existing solution by changing the pitch slightly. Usually, this parameter is taken in the range $[0.1,0.5]$.

The pseudocode of HSA is given in Table 2 .

Table 2. Pseudocode of Harmony Search Algorithm.

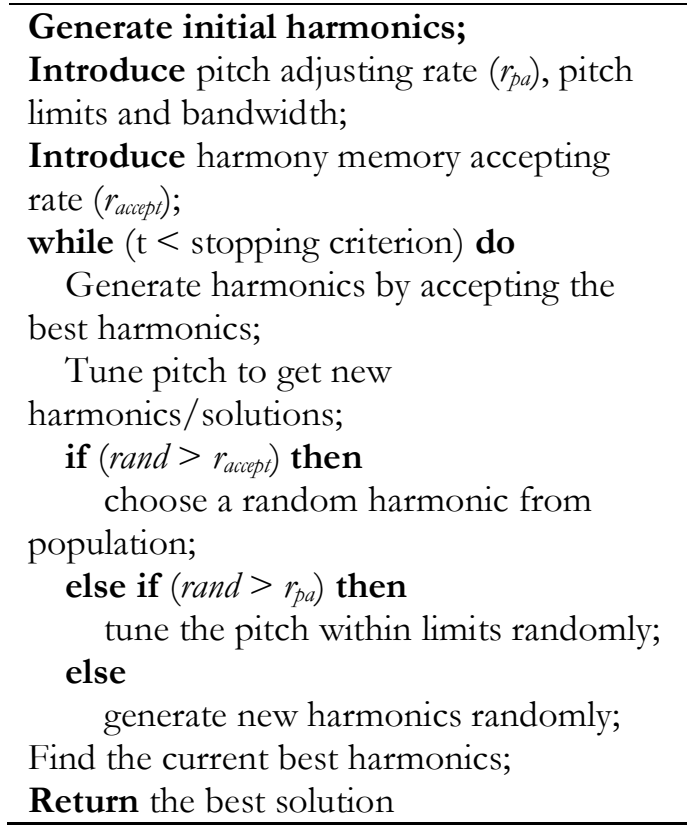

The harmony memory ensures to keep the best harmonies to new harmony memory. It is assigned as a parameter, $r_{\text {accopt }} \in[0,1]$ that is called harmony memory accepting rate. When the rate is too small, a few best harmonies are selected and this causes slower convergence of the HS algorithm. When the rate is too high (a value close to 1), it may not be possible to explore all the harmonies well. This can lead to wrong solutions. The parameter $r_{\text {accept }}$ is selected between [0.7, $0.95]$ to prevent his problem. The pitch adjustment is the second parameter determined by the bandwidth $\left(b_{\text {range }}\right)$ and the adjusting rate of a pitch $r_{p a}$. Pitch adjustment changes the frequencies and generates diversity in the HS. Linear or nonlinear adjustment is used to set the pitch value.

$$
x_{\text {new }}=\mathrm{x}_{\mathrm{old}}+b_{\text {range }} \cdot \varepsilon \text {, }
$$

$x_{\text {old }}$ is the current pitch, and $x_{n e w}$ is the new solution after the adjustment of pitch. This process generates a neighboring solution to the existing solution by changing the pitch slightly. Pitch adjustment mimics like the mutation operator in evolutionary algorithms. A parameter (pitch-adjusting rate $r_{p a}$ ) can be used to control the adjustment level. A small adjustment rate can slow the convergence time of HS, whereas a high adjustment rate can act as a random search process. A value between $[0.1,0.5]$ is observed to be a good balance for $r_{p a}$.

The third parameter (randomization) is used to provide diversified solutions. The randomization enables the system to explore different solutions. The randomization can direct the search to explore various different solutions to obtain the global optimal solutions. the probability of randomization is given below:

$$
p_{\text {random }}=1-r_{\text {accept }}
$$

where the probability of adjusting pitches are:

$$
p_{\text {pitcb }}=r_{\text {accept }} \cdot r_{p a}
$$

Despite significant success of HS applications, several studies have pointed out that search mechanisms of HS exhibit excellent explorative behavior but poor exploitative ability. The memory consideration procedure of the canonical HS is responsible for using the history information of HM to guide the search. Furthermore, the strong exploration ability of HS is due to the memory consideration strategy that selects random harmonies. As a result, the canonical HS presents strong exploration ability but poor exploitation capability. As for the Exploration Ability of Harmony Search Algorithms, in the work [41] four variants of HSA are compared and the results suggest that the exploration capacity of Improved harmony search is better than other algorithms. Paper [42] proposes the best-worst-mean harmony search (BWM_HS) algorithm as a new variant of HS that utilizes more efficiently the valuable information stored in $\mathrm{HM}$ to guide the search process and to balance between the exploration and exploitation abilities during the search course.

After describing these two algorithms, the following question arises: what is the correspondence of the parameters of these algorithms with the inverse problems of chemical kinetics? In the case of the gravitational algorithm, each object in space is a set of kinetic parameters used for mathematical modeling of the chemical process. For the harmonic search algorithm each $s_{i}$ chord that is part of the $H^{M}$ harmony memory matrix is a set of kinetic parameters. In this paper, the kinetic parameters of the chemical process model are understood as a set of activation energies and preexponential factors for each reaction stage, as well as some additional parameters that are necessary to describe the kinetics of the process. For the problem of modeling the propane pre-reforming process, these parameters are $E_{r e f}, E_{\text {met }}, k_{\text {ref }}$, $k_{\text {met }}, B, m$ (see Eq. (3) - (4)), and for the problem of modeling the catalytic isomerization of the pentane-hexane fraction, these parameters are $E_{j}, k_{j}^{0}$ (see Eq. (7)) for each stage of the reaction. 


\subsection{Comparison of GSA and HSA with State-of-the- art Algorithms}

To evaluate the proposed GSA and HSA 20 benchmark functions were used. These functions are classical functions, which are often employed to check the optimization performance of different algorithms. All test functions have been listed in Table 3 , where $D$ indicates dimension of the function, Range is the boundary of the function's search space. The dimension of the functions is 30 , and the global minimum is 0 . Furthermore, $F_{1}-F_{8}$ are unimodal functions, whereas $F_{9}$ $-F_{20}$ are multimodal functions.

To compare the optimization performance among different algorithms we used the next quality indicators. Mean value and standard deviation are good indicators to measure the obtained solution quality. The smaller the mean value is, the stronger the global optimization ability of the algorithm is; the smaller the standard deviation is, the more stability the algorithm is. Table 4 shows the statistical results. In this table $\bar{x}$ and $s$ indicate "mean value" and "standard deviation" respectively. Moreover, the best results are highlighted in bold. Mean value and standard deviation are calculated as follows:

$$
\bar{x}=\frac{1}{n} \sum_{i=1}^{D} x_{i}, \quad s=\sqrt{\frac{1}{n-1} \sum_{i=1}^{D}\left(x_{i}-\bar{x}\right)^{2}} .
$$

We compared the performance between GSA and five state-of-the-art algorithms: Cuckoo Search (CS), Grey Wolf Optimizer (GWO), Whale Optimization Algorithm (WOA), Particle Swarm Optimization (PSO) and Salp Swarm Algorithm (SSA). The statistical results obtained by seven algorithms have been shown in Table 4. The algorithms GSA and HSA show competitiveness compared to the other state-of-the-art algorithms, although the gravitational search algorithm shows better solutions (lower $\bar{x}$ and $s$ values) compared to the harmonic search algorithm.

After testing the algorithm on benchmark functions, the GSA was applied to solve real problems, namely, the inverse problem for the process of propane prereforming into methane-rich gas over $\mathrm{Ni}$ catalyst and catalytic isomerization of the pentane-hexane fraction.

\section{Simulation Results}

\subsection{Propane Pre-reforming into Methane-rich Gas over Ni Catalyst}

The gravitational search algorithm and harmonic search were used to simulate the process of propane prereformation. As a result of solving the inverse problem, the values $E_{r e}, E_{m e t}, k_{r e f}, k_{\text {met }}, B$ and $m$, included in the expression of reaction rates $\mathbb{W}_{\text {ref }}$ and $W_{\text {met, }}$, were optimized. When solving the inverse problem, the values of $E_{r e f}, E_{m e t}, k_{r e f}, k_{\text {met }}$ varied, while the value of $B$ varied from 0 to 5 , and $m$ - from 0 to 2 . The values obtained are shown in Table 5 . The value of the functional $f$ (see Eq. (6)) is presented in the last column of Table 5. It can be seen that the kinetic parameters are approximately the same, and the value of the functional $f$ is also almost the same when solved by different algorithms - GSA and HSA. The values shown in Table 5 are the best solutions obtained by varying the different parameters of the algorithms. The parameters of the harmonic search algorithm for which the best solution was found are as follows: number of improvisations is equal to 1000 , harmony memory size is equal to $100, r_{a c c e p t}=0.95, r_{p a}=$ $0.5, b_{\text {range }}=0.25$. As a result, the running time of the algorithm was about 8 hours.

As for the gravitational algorithm, the best solution was obtained with the following parameters: $G_{0}=250, \alpha$ $=30, z=200$. The solution was obtained in 7 iterations of the algorithm, with a time of about 2 hours.

To sum up, despite the fact that both GSA and HSA algorithms show approximately the same $f$ values, the operating time of the gravitational search algorithm is much shorter, that is, it is preferable to use GSA compared to HSA.

The obtained optimal values were used to solve the direct problem of chemical kinetics. Figure 2 shows the results of calculations for experiments on propane preforming. The figure shows the dependences of the concentrations of the reaction components on the temperature. The points represent experimental data; the curves are the results of modeling the process using the gravitational search algorithm. Propane is consumed during the reaction, so the curve is decreasing. The reaction components $\mathrm{CO}_{2}, \mathrm{H}_{2}, \mathrm{CH}_{4}$ are formed, so the curves increase. The model correctly describes the available experimental data.

\subsection{Catalytic Isomerization of the Pentane-Hexane Fraction}

The studied algorithms were also used to solve the problem of finding the optimal parameters of the catalytic isomerization of the pentane-hexane fraction. If in the previous problem the values of the minimization functional obtained by different algorithms were approximately the same $(f=0.024$ for GSA and $f=0.027$ for HSA), then in this problem there was a noticeable difference. For the process of Catalytic Isomerization of the Pentane-Hexane Fraction, the following values of the minimization functional are obtained: $f=0.22$ for GSA and $\mathrm{f}=0.67$ for HSA. Apparently, the harmonic search algorithm falls into the local minimum, which prevents it from reaching the global optimum. Therefore, as a solution to the problem, the kinetic parameters obtained by the gravitational search algorithm are taken, which are presented in Table 6. Table 6 represents stages of the process and corresponding kinetic parameters. 
Table 3. Benchmark functions.

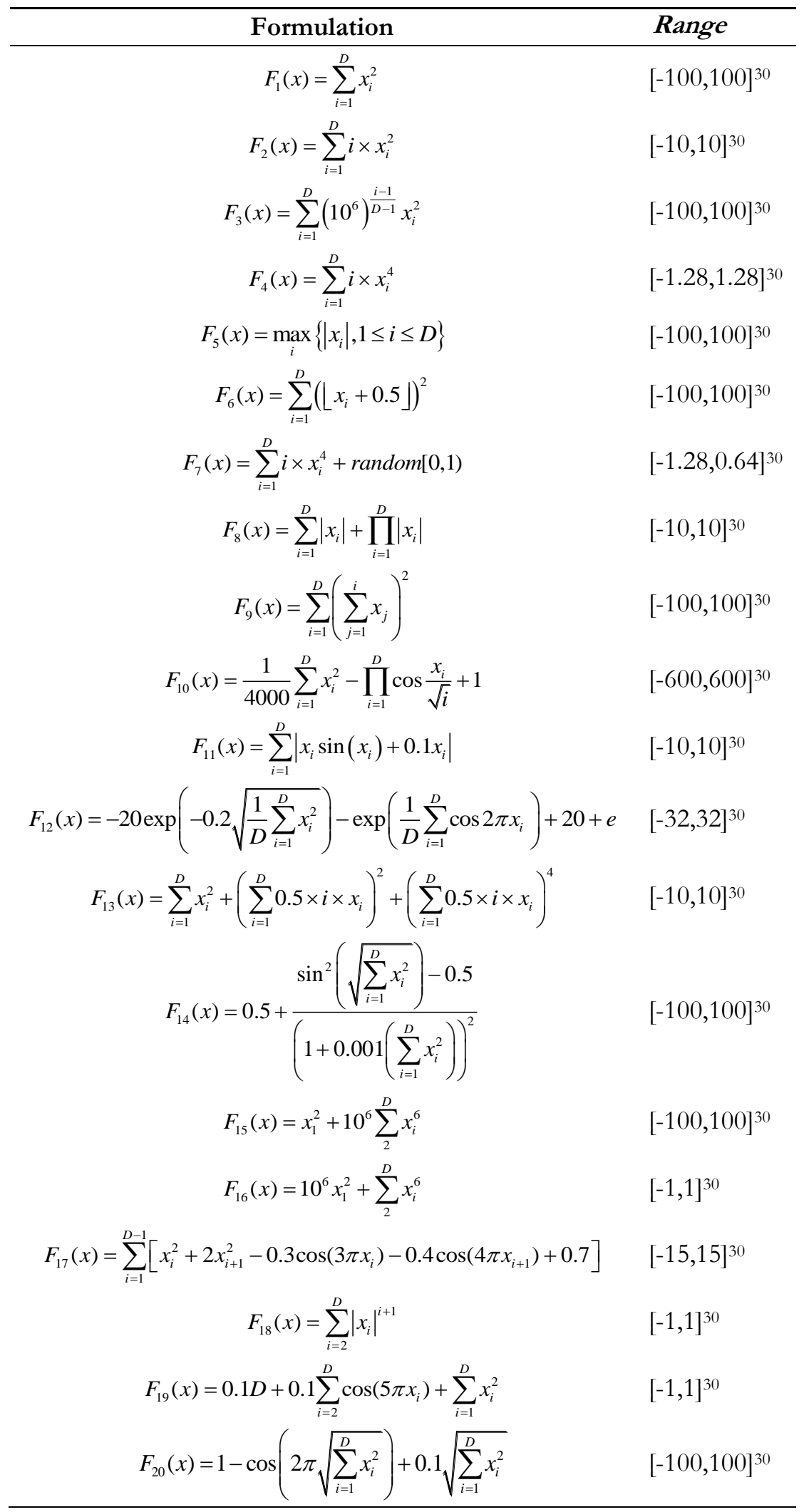


Table 4. The experimental results for five benchmark functions obtained by 7 metaheuristic algorithms.

\begin{tabular}{|c|c|c|c|c|c|c|c|c|}
\hline No & & $\mathrm{CS}$ & GWO & WOA & PSO & SSA & GSA & HSA \\
\hline \multirow[t]{2}{*}{$F_{1}$} & $\bar{x}$ & 0 & 0 & 0 & 0 & $4.81 \cdot 10^{-9}$ & $2.02 \cdot 10^{-10}$ & $-7.58 \cdot 10^{-5}$ \\
\hline & $s$ & 0 & 0 & 0 & 0 & $1.06 \cdot 10^{-9}$ & $1.06 \cdot 10^{-9}$ & $3.01 \cdot 10^{-3}$ \\
\hline \multirow[t]{2}{*}{$F_{2}$} & $x^{-}$ & 0 & 0 & 0 & 0 & $1.03 \cdot 10^{-8}$ & $2.25 \cdot 10^{-2}$ & $-8.44 \cdot 10^{-2}$ \\
\hline & $s$ & 0 & 0 & 0 & 0 & $2.51 \cdot 10^{-9}$ & 0.15 & 0.46 \\
\hline \multirow[t]{2}{*}{$\mathrm{F}_{3}$} & $\bar{x}^{-}$ & 0 & 0 & 0 & 0 & $1.46 \cdot 10^{-6}$ & $1.67 \cdot 10^{-1}$ & $1.07 \cdot 10^{-4}$ \\
\hline & $s$ & 0 & 0 & 0 & 0 & $6.06 \cdot 10^{-5}$ & 1.72 & $2.5 \cdot 10^{-3}$ \\
\hline \multirow[t]{2}{*}{$F_{4}$} & $x^{-}$ & 0 & 0 & 0 & 0 & $1.52 \cdot 10^{-24}$ & $-5.48 \cdot 10^{-4}$ & $-1.41 \cdot 10^{-5}$ \\
\hline & $s$ & 0 & 0 & 0 & 0 & $6.28 \cdot 10^{-25}$ & $2.88 \cdot 10^{-3}$ & $3.79 \cdot 10^{-5}$ \\
\hline \multirow[t]{2}{*}{$F_{5}$} & $\bar{x}^{-}$ & 16.6 & 0 & 12.8 & $3.24 \cdot 10^{-5}$ & 1.27 & $-2.22 \cdot 10^{-15}$ & $-6.06 \cdot 10^{-11}$ \\
\hline & $s$ & 4.13 & 0 & 19.4 & $3.59 \cdot 10^{-5}$ & 1.53 & $1.49 \cdot 10^{-14}$ & $1.07 \cdot 10^{-9}$ \\
\hline \multirow[t]{2}{*}{$F_{6}$} & $\bar{x}^{-}$ & 0 & 0 & 0 & $4.67 \cdot 10^{-1}$ & 7.5 & $1.84 \cdot 10^{-2}$ & $-7.09 \cdot 10^{-2}$ \\
\hline & $s$ & 0 & 0 & 0 & $9.00 \cdot 10^{-1}$ & 4.35 & 0.23 & 0.26 \\
\hline \multirow[t]{2}{*}{$F_{7}$} & $\bar{x}^{-}$ & $9.32 \cdot 10^{-2}$ & $1.32 \cdot 10^{-4}$ & $3.17 \cdot 10^{-4}$ & $4.27 \cdot 10^{-3}$ & $1.87 \cdot 10^{-2}$ & $1.48 \cdot 10^{-2}$ & $-1.23 \cdot 10^{-3}$ \\
\hline & $s$ & $3.60 \cdot 10^{-2}$ & $8.97 \cdot 10^{-5}$ & $5.08 \cdot 10^{-4}$ & $2.12 \cdot 10^{-3}$ & $6.01 \cdot 10^{-3}$ & 0.07 & $2.43 \cdot 10^{-2}$ \\
\hline \multirow[t]{2}{*}{$F_{8}$} & $x^{-}$ & 0 & 0 & 0 & 0 & $5.24 \cdot 10^{-1}$ & $1,75 \cdot 10^{-10}$ & $4.02 \cdot 10^{-4}$ \\
\hline & $s$ & 0 & 0 & 0 & 0 & $7.33 \cdot 10^{-1}$ & $1.14 \cdot 10^{-9}$ & $2.44 \cdot 10^{-3}$ \\
\hline \multirow[t]{2}{*}{$F_{9}$} & $x^{-}$ & $2.72 \cdot 10^{-2}$ & 0 & 75.7 & $5.67 \cdot 10^{-8}$ & $2.92 \mathrm{E}-07$ & $1.12 \cdot 10^{-1}$ & -2.42 \\
\hline & $s$ & $2.92 \cdot 10^{-2}$ & 0 & 72.8 & $7.01 \cdot 10^{-8}$ & $9.01 \mathrm{E}-08$ & 0.61 & 13.25 \\
\hline \multirow[t]{2}{*}{$F_{10}$} & $x^{-}$ & $7.45 \cdot 10^{-3}$ & 0 & $4.14 \cdot 10^{-4}$ & $1.88 \cdot 10^{-2}$ & $6.73 \cdot 10^{-3}$ & $5.93 \cdot 10^{-9}$ & $1.11 \cdot 10^{-1}$ \\
\hline & $s$ & $1.68 \cdot 10^{-2}$ & 0 & $2.27 \cdot 10^{-3}$ & $1.95 \cdot 10^{-2}$ & $7.17 \cdot 10^{-3}$ & $1.94 \cdot 10^{-8}$ & 1.78 \\
\hline \multirow[t]{2}{*}{$F_{11}$} & $x^{-}$ & $3.89 \cdot 10^{-1}$ & 0 & 0 & $1.29 \cdot 10^{-15}$ & 2.65 & $-3.45 \cdot 10^{-2}$ & $-5.54 \cdot 10^{-2}$ \\
\hline & $s$ & $2.25 \cdot 10^{-1}$ & 0 & 0 & 0 & 1.63 & 0.05 & 0.04 \\
\hline \multirow[t]{2}{*}{$F_{12}$} & $x^{-}$ & 2 & 0 & 0 & $8.88 \cdot 10^{-1}$ & 2.18 & $-2.65 \cdot 10^{-10}$ & $4.75 \cdot 10^{-3}$ \\
\hline & $s$ & 1.13 & 0 & 0 & $8.87 \cdot 10^{-1}$ & $5.88 \cdot 10^{-1}$ & $5.15 \cdot 10^{-10}$ & $1.88 \cdot 10^{-2}$ \\
\hline \multirow[t]{2}{*}{$F_{13}$} & $x^{-}$ & $2.58 \cdot 10^{-3}$ & 0 & 0 & $1.05 \cdot 10^{-13}$ & $2.65 \mathrm{E}-10$ & $1.06 \cdot 10^{-1}$ & $1.50 \cdot 10^{-2}$ \\
\hline & $s$ & $7.78 \cdot 10^{-3}$ & 0 & 0 & $1.26 \cdot 10^{-13}$ & $9.34 \mathrm{E}-11$ & 0.69 & 0.16 \\
\hline \multirow[t]{2}{*}{$F_{14}$} & $\bar{x}^{-}$ & $4.00 \cdot 10^{-2}$ & $3.13 \cdot 10^{-3}$ & $6.65 \cdot 10^{2}$ & $9.07 \cdot 10^{-3}$ & $1.16 \mathrm{E}-02$ & $2.40 \cdot 10^{-1}$ & $-1.53 \cdot 10^{-3}$ \\
\hline & $s$ & $2.49 \cdot 10^{-2}$ & $1.47 \cdot 10^{-11}$ & $1.49 \cdot 10^{1}$ & $3.45 \cdot 10^{-3}$ & $2.20 \mathrm{E}-03$ & 2.32 & 0.61 \\
\hline \multirow[t]{2}{*}{$F_{15}$} & $x^{-}$ & 0 & 0 & $2.29 \cdot 10^{-3}$ & 0 & $4.89 \cdot 10^{-9}$ & $2.22 \cdot 10^{-2}$ & $1.33 \cdot 10^{-3}$ \\
\hline & $s$ & 0 & 0 & $1.41 \cdot 10^{-3}$ & 0 & $8.50 \cdot 10^{-10}$ & 0.12 & $2.65 \cdot 10^{-3}$ \\
\hline \multirow[t]{2}{*}{$F_{16}$} & $x^{-}$ & 0 & 0 & 0 & 0 & $3.21 \cdot 10^{-1}$ & $-9.15 \cdot 10^{-3}$ & $4.57 \cdot 10^{-6}$ \\
\hline & $s$ & 0 & 0 & 0 & 0 & $1.96 \cdot 10^{-1}$ & $7.83 \cdot 10^{-2}$ & $5.66 \cdot 10^{-5}$ \\
\hline \multirow[t]{2}{*}{$F_{17}$} & $x^{-}$ & 5.73 & 0 & 0 & 4.1 & $1.06 \cdot 10^{-1}$ & $1.57 \cdot 10^{-1}$ & $4.50 \cdot 10^{-4}$ \\
\hline & $s$ & 2.27 & 0 & 0 & 2.16 & 2.41 & $1.20 \cdot 10^{-9}$ & $6.14 \cdot 10^{-3}$ \\
\hline \multirow[t]{2}{*}{$F_{18}$} & $x^{-}$ & 0 & 0 & 0 & 0 & $4.71 \cdot 10^{-8}$ & $7.68 \cdot 10^{-3}$ & $-2.99 \cdot 10^{-3}$ \\
\hline & $s$ & 0 & 0 & 0 & 0 & $2.28 \cdot 10^{-8}$ & 0.04 & $4.95 \cdot 10^{-2}$ \\
\hline \multirow[t]{2}{*}{$F_{19}$} & $\bar{x}^{-}$ & $7.39 \cdot 10^{-2}$ & 0 & 0 & $5.37 \cdot 10^{-1}$ & 1.26 & 0 & $-7.08 \cdot 10^{-7}$ \\
\hline & $s$ & $7.52 \cdot 10^{-2}$ & 0 & 0 & $2.89 \cdot 10^{-1}$ & $2.42 \cdot 10^{-1}$ & 0 & $3.82 \cdot 10^{-5}$ \\
\hline \multirow[t]{2}{*}{$F_{20}$} & $x^{-}$ & $7.80 \cdot 10^{-1}$ & $1.13 \cdot 10^{-1}$ & $1.17 \cdot 10^{-1}$ & $4.37 \cdot 10^{-1}$ & $5.23 \cdot 10^{-1}$ & $9.79 \cdot 10^{-2}$ & $-5.12 \cdot 10^{-2}$ \\
\hline & $s$ & $1.88 \cdot 10^{-2}$ & $3.46 \cdot 10^{-2}$ & $5.92 \cdot 10^{-2}$ & $9.64 \cdot 10^{-2}$ & $9.35 \cdot 10^{-2}$ & 0.36 & 0.37 \\
\hline
\end{tabular}

Figure 3 represents calculated concentration profiles of individual components in all three reactors (vertical lines separating the profiles characterize the three reactors). Inlet data of the first reactor and outlet data of the last reactor were the only obtained manufacturing data for the reactions (highlighted by markers on figures).
Figure 4 represents the temperature profile in reactors that accounts cooling of the reaction mixture after the second reactor. Gradual increase of temperature witnesses moderate isothermal effect of the isomerization reactions.

It is worth noting that the number of required parameters was 96 (for each of the 48 reaction stages in 
Table 6, it was necessary to calculate the values of the activation energy and the pre-exponential factor), but the initial data were only 3 sets of experimental data for 17 observed reaction components, so this problem has an infinite set of solutions. According to Figs. 3 and 4, it can be concluded that the developed kinetic model correctly describes the data not only on the concentrations of the components, but also the temperature of the reaction. The adequacy of the data is also confirmed by the fact that the kinetic parameters of the reaction presented in Table 6 were initially selected experimentally by solving a direct problem, and then refined by varying from the starting point within 30 percent.

Table 5. The values $E_{\text {ref }}, E_{\text {met }}, k_{\text {ref }}, k_{\text {met }}, B$ and $m$ obtained as a result of solving the inverse problem by gravitational search and harmony search algorithms.

\begin{tabular}{cccccccc}
\hline Algorithm & Eref, $\mathbf{~ J J} / \mathbf{m o l}$ & Emet, $\mathbf{~ J J} / \mathbf{m o l}$ & $\mathbf{k}_{\text {ref }},\left(\mathbf{m o l e} \cdot \mathbf{m}^{-3}\right)^{\mathbf{m}} \cdot \mathbf{s}^{-1}$ & $\mathbf{k}_{\text {met }}, \mathbf{s}^{-1}$ & $\mathbf{m}$ & $\mathbf{B}$ & $\boldsymbol{f}$ \\
\hline GSA & 103.2 & 37.0 & $10^{10}$ & $4.6 \cdot 10^{4}$ & 1.07 & $2.2 \cdot 10^{-1}$ & $2.4 \cdot 10^{-2}$ \\
\hline HSA & 110.3 & 52.4 & $4.1 \cdot 10^{10}$ & $1.9 \cdot 10^{6}$ & 1.10 & $2.2 \cdot 10^{-1}$ & $2.7 \cdot 10^{-2}$ \\
\hline
\end{tabular}

Table 6. Kinetic parameters of the catalytic isomerization of the pentane-hexane fraction. Here are 2-MP is 2-methyl pentane, 3-MP is 3-methyl pentane, 2,2-DMB is 2,2-dimethyl butane, 2,3-DMB is 2,3-dimethyl butane, $\mathrm{CH}^{*}$ is cyclohexane, MCP is methyl cyclopentane, B is benzene.

\begin{tabular}{|c|c|c|c|c|c|c|c|}
\hline No & Reaction & $\begin{array}{c}E, \\
\mathrm{~kJ} / \mathrm{mol}\end{array}$ & $\lg \left(k^{0}\right)$ & No & Reaction & $\begin{array}{c}E, \\
\mathrm{~kJ} / \mathrm{mol}\end{array}$ & $\lg \left(k^{0}\right)$ \\
\hline 1 & $\mathrm{n}-\mathrm{C}_{5} \mathrm{H}_{12} \rightarrow$ iso- $\mathrm{C}_{5} \mathrm{H}_{12}$ & 148.93 & 15.74 & 25 & $\begin{array}{c}\mathrm{n}-\mathrm{C}_{6} \mathrm{H}_{14} \rightarrow \mathrm{CH} \text { (cyclohexane*) } \\
+\mathrm{H}_{2}\end{array}$ & 129.75 & 9.87 \\
\hline 2 & iso- $\mathrm{C}_{5} \mathrm{H}_{12} \rightarrow \mathrm{n}-\mathrm{C}_{5} \mathrm{H}_{12}$ & 154.28 & 15.92 & 26 & $\begin{array}{c}\mathrm{CH}^{*}(\text { cyclohexane })+\mathrm{H}_{2} \rightarrow \mathrm{n}- \\
\mathrm{C}_{6} \mathrm{H}_{14}\end{array}$ & 88.64 & 6.83 \\
\hline 3 & $\mathrm{n}-\mathrm{C}_{6} \mathrm{H}_{14} \rightarrow 2-\mathrm{MP}$ & 143.17 & 7.59 & 27 & $2-\mathrm{MP} \rightarrow \mathrm{MCP}+\mathrm{H}_{2}$ & 135.45 & 13.17 \\
\hline 4 & $2-\mathrm{MP} \rightarrow \mathrm{n}-\mathrm{C}_{6} \mathrm{H}_{14}$ & 151.41 & 7.68 & 28 & $\mathrm{MCP}+\mathrm{H}_{2} \rightarrow 2-\mathrm{MP}$ & 129.29 & 8.31 \\
\hline 5 & $\mathrm{n}-\mathrm{C}_{6} \mathrm{H}_{14} \rightarrow 3-\mathrm{MP}$ & 150.98 & 18.08 & 29 & $3-\mathrm{MP} \rightarrow \mathrm{MCP}+\mathrm{H}_{2}$ & 154.54 & 14.86 \\
\hline 6 & $3-\mathrm{MP} \rightarrow \mathrm{n}-\mathrm{C}_{6} \mathrm{H}_{14}$ & 155.92 & 18.53 & 30 & $\mathrm{MCP}+\mathrm{H}_{2} \rightarrow 3-\mathrm{MP}$ & 98.63 & 10.18 \\
\hline 7 & $2-\mathrm{MP} \rightarrow 3-\mathrm{MP}$ & 152.96 & 16.19 & 31 & $2,2-\mathrm{DMB} \rightarrow \mathrm{MCP}+\mathrm{H}_{2}$ & 150.29 & 13.80 \\
\hline 8 & $3-\mathrm{MP} \rightarrow 2-\mathrm{MP}$ & 149.95 & 16.19 & 32 & $\mathrm{MCP}+\mathrm{H}_{2} \rightarrow 2,2-\mathrm{DMB}$ & 102.35 & 6.99 \\
\hline 9 & $2-\mathrm{MP} \rightarrow 2,2-\mathrm{DMB}$ & 127.28 & 11.46 & 33 & $2,3-\mathrm{DMB} \rightarrow \mathrm{MCP}+\mathrm{H}_{2}$ & 168.13 & 11.36 \\
\hline 10 & $2,2-\mathrm{DMB} \rightarrow 2-\mathrm{MP}$ & 139.07 & 12.91 & 34 & $\mathrm{MCP}+\mathrm{H}_{2} \rightarrow 2,3-\mathrm{DMB}$ & 90.70 & 6.00 \\
\hline 11 & $2-\mathrm{MP} \rightarrow 2,3-\mathrm{DMB}$ & 64.50 & 5.06 & 35 & $\mathrm{CP}+\mathrm{H}_{2} \rightarrow \mathrm{n}-\mathrm{C}_{5} \mathrm{H}_{12}$ & 177.32 & 20.89 \\
\hline 12 & $2,3-\mathrm{DMB} \rightarrow 2-\mathrm{MP}$ & 77.06 & 6.97 & 36 & $\mathrm{n}-\mathrm{C}_{5} \mathrm{H}_{12} \rightarrow \mathrm{CP}+\mathrm{H}_{2}$ & 222.90 & 10.85 \\
\hline 13 & $3-\mathrm{MP} \rightarrow 2,2-\mathrm{DMB}$ & 146.14 & 10.68 & 37 & $\mathrm{n}-\mathrm{C}_{4} \mathrm{H}_{10} \rightarrow$ iso- $\mathrm{C}_{4} \mathrm{H}_{10}$ & 59.80 & 12.71 \\
\hline 14 & $2,2-\mathrm{DMB} \rightarrow 3-\mathrm{MP}$ & 160.28 & 11.82 & 38 & iso- $\mathrm{C}_{4} \mathrm{H}_{10} \rightarrow \mathrm{n}-\mathrm{C}_{4} \mathrm{H}_{10}$ & 54.08 & 11.51 \\
\hline 15 & $3-\mathrm{MP} \rightarrow 2,3-\mathrm{DMB}$ & 98.28 & 9.65 & 39 & $\mathrm{n}-\mathrm{C}_{5} \mathrm{H}_{12}+\mathrm{H}_{2} \rightarrow \mathrm{C}_{3} \mathrm{H}_{8}+\mathrm{C}_{2} \mathrm{H}_{6}$ & 330.28 & 10.48 \\
\hline 16 & $2,3-\mathrm{DMB} \rightarrow 3-\mathrm{MP}$ & 105.40 & 10.65 & 40 & $\mathrm{n}-\mathrm{C}_{5} \mathrm{H}_{12}+\mathrm{H}_{2} \rightarrow \mathrm{n}-\mathrm{C}_{4} \mathrm{H}_{10}+\mathrm{CH}_{4}$ & 329.06 & 25.18 \\
\hline 17 & $2,2-\mathrm{DMB} \rightarrow 2,3-\mathrm{DMB}$ & 3.51 & 3.40 & 41 & 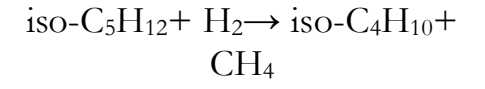 & 284.97 & 30.17 \\
\hline 18 & $2,3-\mathrm{DMB} \rightarrow 2,2-\mathrm{DMB}$ & 4.79 & 3.93 & 42 & $\mathrm{n}-\mathrm{C}_{6} \mathrm{H}_{14}+\mathrm{H}_{2} \rightarrow 2 \mathrm{C}_{3} \mathrm{H}_{8}$ & 166.32 & 10.24 \\
\hline 19 & $\begin{array}{l}\mathrm{B}+3 \mathrm{H}_{2} \rightarrow \mathrm{CH}^{*} \\
\text { (cyclohexane) }\end{array}$ & 180.20 & 30.47 & 43 & $\mathrm{n}-\mathrm{C}_{6} \mathrm{H}_{14}+\mathrm{H}_{2} \rightarrow \mathrm{n}-\mathrm{C}_{5} \mathrm{H}_{12}+\mathrm{CH}_{4}$ & 165.82 & 10.30 \\
\hline 20 & $\begin{array}{c}\mathrm{CH}^{*}(\text { cyclohexane }) \\
\mathrm{B}+3 \mathrm{H}_{2}\end{array}$ & 400.43 & 23.00 & 44 & $\begin{array}{c}\mathrm{n}-\mathrm{C}_{6} \mathrm{H}_{14}+\mathrm{H}_{2} \rightarrow \mathrm{n}-\mathrm{C}_{4} \mathrm{H}_{10}+ \\
\mathrm{C}_{2} \mathrm{H}_{6}\end{array}$ & 112.05 & 9.80 \\
\hline 21 & $\mathrm{~B}+3 \mathrm{H}_{2} \rightarrow \mathrm{MCP}$ & 187.05 & 26.46 & 45 & $\begin{array}{c}2-\mathrm{MP}+\mathrm{H}_{2} \rightarrow \text { iso }-\mathrm{C}_{4} \mathrm{H}_{10}+ \\
\mathrm{C}_{2} \mathrm{H}_{6}\end{array}$ & 265.00 & 24.85 \\
\hline 22 & $\mathrm{MCP} \rightarrow \mathrm{B}+3 \mathrm{H}_{2}$ & 300.79 & 25.00 & 46 & $3-\mathrm{MP}+\mathrm{H}_{2} \rightarrow$ iso- $\mathrm{C}_{5} \mathrm{H}_{12}+\mathrm{CH}_{4}$ & 295.62 & 30.65 \\
\hline 23 & $\begin{array}{c}\mathrm{CH}^{*}(\text { cyclohexane }) \\
\text { MCP }\end{array}$ & 51.08 & 3.164 & 47 & $\begin{array}{c}2,2-\mathrm{DMB}+\mathrm{H}_{2} \rightarrow \text { iso- } \mathrm{C}_{5} \mathrm{H}_{12}+ \\
\mathrm{CH}_{4}\end{array}$ & 294.00 & 4.40 \\
\hline 24 & $\begin{array}{l}\mathrm{MCP} \rightarrow \mathrm{CH}^{*} \\
\text { (cyclohexane) }\end{array}$ & 341.89 & 2.80 & 48 & $\begin{array}{c}2,3-\mathrm{DMB}+\mathrm{H}_{2} \rightarrow \mathrm{iso}^{-\mathrm{C}_{5} \mathrm{H}_{12}+} \\
\mathrm{CH}_{4}\end{array}$ & 278.81 & 19.84 \\
\hline
\end{tabular}




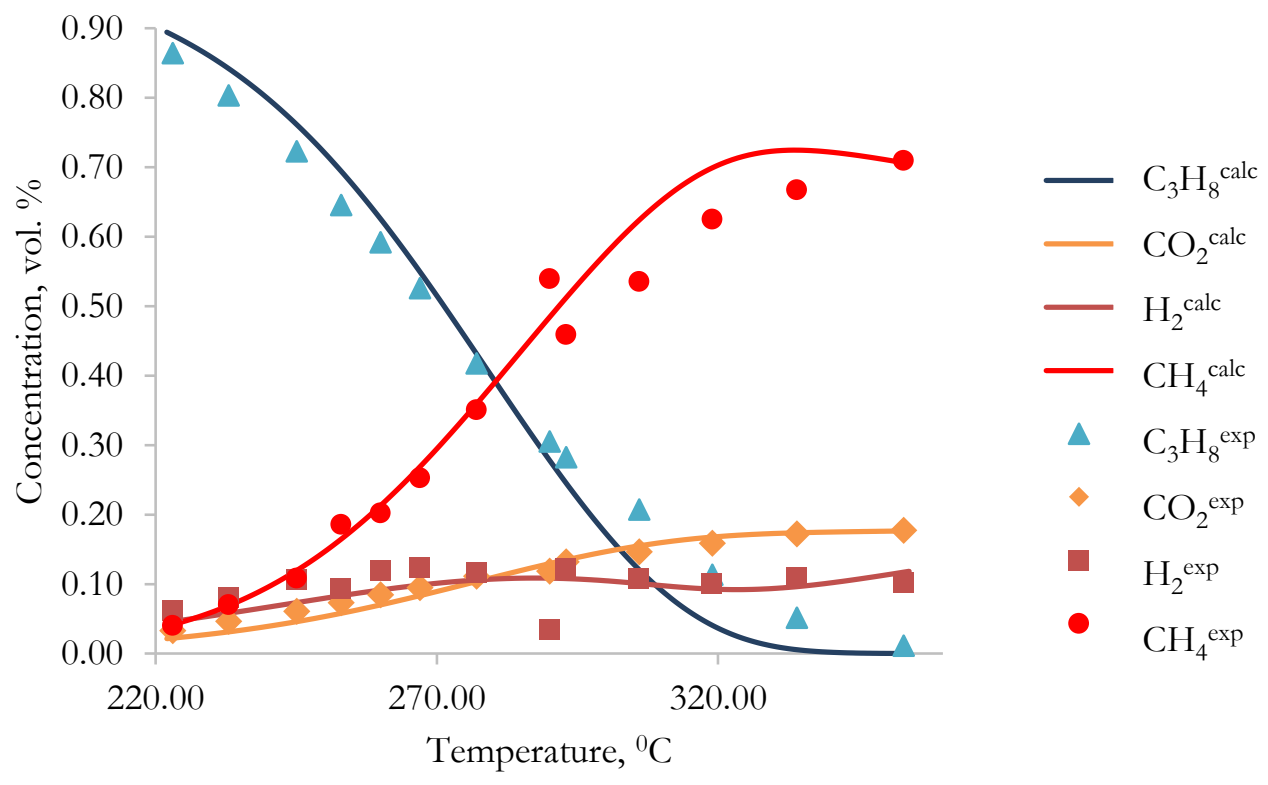

Fig. 2. Temperature dependences of the output concentrations of propane $\mathrm{C}_{3} \mathrm{H}_{8}$, methane $\mathrm{CH}_{4}$, hydrogen $\mathrm{H}_{2}$ and $\mathrm{CO}_{2}$ in the process of propane pre-reforming. Experimental conditions: $220-380{ }^{\circ} \mathrm{C}$, GHSV $4000 \mathrm{~h}^{-1}$, 1 bar pressure, reaction mixture: 25 vol. $\% \mathrm{C}_{3} \mathrm{H}_{8}, 75$ vol. $\% \mathrm{H}_{2} \mathrm{O}$. Concentrations of the gas components on the figure are given on the dry basis. Points are experimental concentrations ("exp"-index), lines are simulated concentrations ("calc"-index).
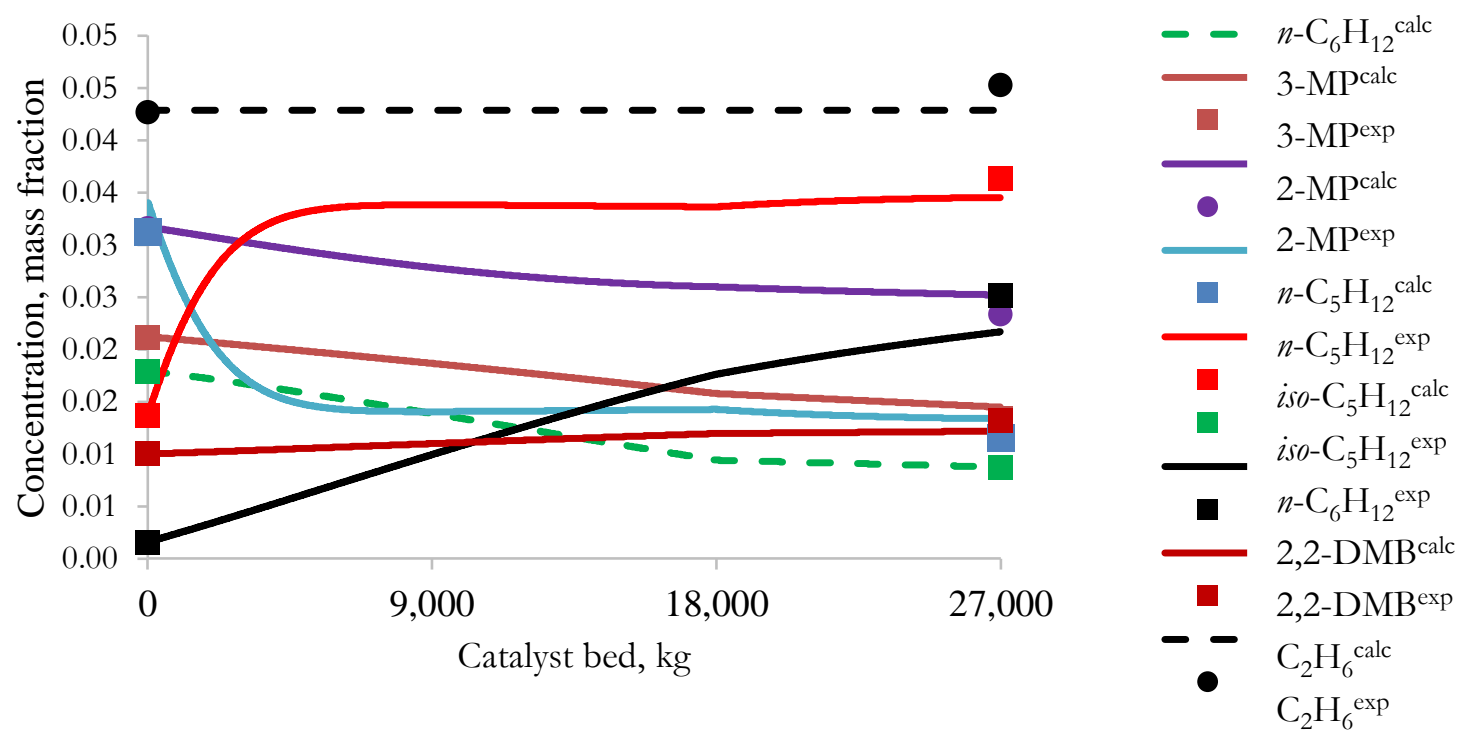

Fig. 3. 2,3-dimethyl butane (2,3-DMB), n-hexane (n- $\mathrm{C}_{6} \mathrm{H}_{14}$ ), 3-methyl pentane (3-MP), 2-methyl pentane (2-MP) and ethane $\left(\mathrm{C}_{3} \mathrm{H}_{8}\right)$ concentrations profiles. Vertical lines correspond to the reactor section zones I, II and III.

\section{Conclusions}

This study shows the application of two heuristic algorithms - the gravitational search algorithm and the harmonic search algorithm - for solving inverse problems of chemical kinetics. At first, the effectiveness of the algorithms was tested on benchmark functions, where the best solution was demonstrated by the gravitational search algorithm compared to the harmony search algorithm according to the mean value and standard deviation criteria. Further, these algorithms were used to find the kinetic parameters of the propane pre-reforming reaction on the Ni-catalyst and catalytic isomerization of the pentane-hexane fraction. In first problem, both algorithms showed approximately the same result, apparently because there are only 6 optimized parameters in this problem. However, for the searching problem for the isomerization parameters of the pentane-hexane fraction, the results of the gravitational algorithm far exceed the results of the harmonic search algorithm. 
Apparently, this is since there is large-scale problem - 96 parameters. The calculations showed that both algorithms take place when solving optimization problems, however, the harmony search algorithm is better used on low-dimensional problems, while the gravitational search algorithm gives good results on various-scale problems in a sufficient acceptable time. According to the results, GSA can offer better solutions for studied inverse problems of chemical kinetics than the HSA in terms of solutions quality and computational efficiency.

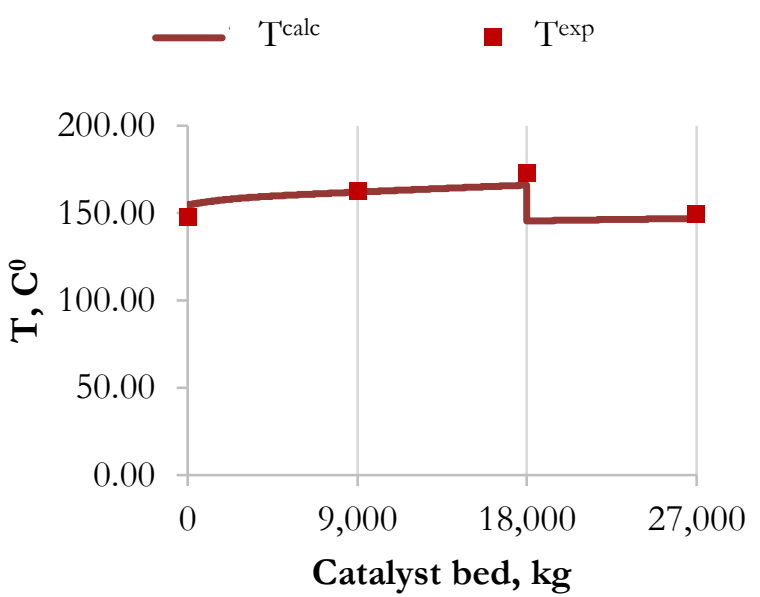

Fig. 4. Temperature profile. Vertical lines correspond to the reactor section zones I-III. The dots marked as Texp represent industrial data, and the $T^{\text {calc }}$ line shows the numerical solution of Eq. (8) to describe the reaction temperature.

Thus, as a result of this work, a software package has been developed that solves inverse problems of chemical kinetics by two heuristic methods. The programs are written in the Python programming language in the PyCharm development environment. The following libraries were used: numpy, scipy, matplotlib. In the future, this software package is planned to be supplemented with other optimization methods, as well as to solve the problems of modeling new chemical processes.

\section{Acknowledgement}

The reported study was funded by RFBR (project number 19-37-60014) and Russian Science Foundation grant (project number 21-71-20047).

\section{References}

[1] Z. Yiying and J. Zhigang, "Group teaching optimization algorithm: A novel metaheuristic method for solving global optimization problems," Expert Systems with Applications, vol. 148, p. 113246, 2020.

[2] M. Nazarahari, E. Khanmirza, and S. Doostie "Multi-objective multi-robot path planning in continuous environment using an enhanced genetic algorithm," Expert Systems with Applications, vol. 115, pp. 106-120, 2019.

[3] Y. Kuroki, G. S. Young, and S. E. Haupt, "UAV navigation by an expert system for contaminant mapping with a genetic algorithm," Expert Systems with Applications, vol. 37, no. 6, pp. 4687-4697, 2010.

[4] A. Zareie, A. Sheikhahmadi, and M. Jalili, "Identification of influential users in social network using gray wolf optimization algorithm," Expert Systems with Applications, vol. 142, p. 112971, 2020.

[5] K. V. Kazantsev, L. Bikmetova, O. Dzhikiya, M. Smolikov, and A. S. Belyi, "Particle swarm optimization for inverse chemical kinetics problem solving as applied to n-hexane isomerization on sulfated zirconia catalysts," Procedia Engineering, vol. 152, pp. 34-39, 2016.

[6] P. C. Pontes and C. P. Naveira-Cotta "Inverse problem analysis for identification of reaction kinetics constants in microreactors for biodiesel synthesis," Journal of Physics: Conference Series, vol. 745, p. 032101, 2016.

[7] I. Gubaydullin, L. Enikeeva, and L. R. Naik, "Software module of Mathematical Chemistry weblaboratory for studying the kinetics of oxidation of 4-tert-butyl-phenol by aqueous solution of H2O2 in the presence of titanosilicates," Engineering Journal, vol. 20, no. 5, pp. 263-270, 2016.

[8] L. F. Akhmadullina, L. V. Enikeeva, and I. M. Gubaydullin, "Numerical methods for reaction kinetics parameters: Identification of lowtemperature propane conversion in the presence of methane," Procedia Engineering, vol. 201, pp. 612-616, 2017.

[9] I. Ryzhikov, C. Brester, and E. Semenkin "Multiobjective dynamical system parameters and initial value identification approach in chemical disintegration reaction modelling," in ICINCO 2017 - Proceedings of the 14th International Conference on Informatics in Control, Automation and Robotics, 2017, vol. 1, pp. 497-504.

[10] A. Taghipour and A. Naderifar "Kinetic modeling of vacuum residue thermal cracking in the visbreaking process using multiobjective optimization," Energy Technol., vol. 3, pp. 758 -767, 2015.

[11] J. Cutillas-Lozano and D. Gimenez "Using hyperheuristics to improve the determination of the kinetic constants of a chemical reaction in heterogeneous phase," in Procedia Computer Science, ICCS 2014. 14th International Conference on Computational Science, 2014, vol. 29, pp. 1345-1355.

[12] T. Ganesan, I. Elamvazuthi, Ku Shaari, Ku Zilati, and P. Vasant, "Swarm intelligence and gravitational search algorithm for multi-objective optimization of synthesis gas production," Appl. Energy, vol. 103, pp. 368-374, 2013.

[13] S. Ma, Y. Dong, Z. Sang, and S. Li., "An improved AEA algorithm with Harmony Search (HSAEA) 
and its application in reaction kinetic parameter estimation," Applied Soft Computing, vol. 13, no. 8, pp 3505-3514, 2013.

[14] A. Bhattacharya and P. K. Roy, "Solution of multiobjective optimal powerflow using gravitational search algorithm," IET Gener., Transm. Distrib., vol. 6, no 8, pp. 751-763, 2012.

[15] M. S. Jahan and N. Amjady, "Solution of large-scale security constrained optimal power flow by a new bi-level optimisation approach based on enhanced gravitational search algorithm," IET Gener., Transm. Distrib., vol. 7, no. 12, 2013.

[16] S. Duman, U. Guvenc, Y. Sönmez, and N. Yörükeren, "Optimal powerflow using gravitational search algorithm," Energy Convers. Manag., vol. 59, pp. 86-95, 2012.

[17] J. Sarker and S. K. Goswami, "Solution of multiple UPFC placement problems using Gravitational Search Algorithm," Int. J. Electr. Power Energy Syst., vol. 55, pp. 531-541, 2014.

[18] B. Shaw, V. Mukherjee, and S. P. Ghoshal, "Solution of reactive power dispatch of power systems by an opposition-based gravitational search algorithm," Int. J. Electr. Power Energy Syst., vol. 55, pp. 29-40, 2014.

[19] S. Mondal, A. Bhattacharya, and S. H. nee Dey, "Multi-objective economic emission load dispatch solution using gravitational search algorithm and considering wind power penetration," Int. J. Electr. Power Energy Syst., vol. 44, no. 1, pp. 282-292, 2013.

[20] T. Niknam, M. R. Narimani, R. AzizipanahAbarghooee, and B. Bahmani-Firouzi, "Multiobjective optimal reactive power dispatch and voltage control: a new opposition-based selfadaptive modified gravitational search algorithm," Syst. J. IEEE, vol. 7, no. 4, pp. 742-753, 2013.

[21] S. Jiang, Z. Ji, and Y. Shen, "A novel hybrid particle swarm optimization and gravitational search algorithm for solving economic emission load dispatch problems with various practical constraints," Int. J. Electr. Power Energy Syst., vol. 55, pp. 628-644, 2014.

[22] T. Chakraborti and A. Chatterjee, "A novel binary adaptive weight GSA based feature selection for face recognition using local gradient patterns, modified census transform, and local binary patterns," Eng. Appl. Artif. Intell., vol. 33, pp. 80-90, 2014.

[23] X. Han, X. Xiong, and F. Duan, "A new method for image segmentation based on BP neural network and gravitational search algorithm enhanced by cat chaotic mapping," Appl. Intell., vol. 43, no. 4, pp. 855-873, 2015.

[24] E. Rashedi, E. Rashedi, and H. Nezamabadipour, "A comprehensive survey on gravitational search algorithm," Swarm and Evolutionary Computation, vol. 41, pp. 141-158, 2018.

[25] P. Jaeyoung, K. Soonyoung, K. Minho, and H. Soohee, "A cascaded improved harmony search for line impedance estimation in a radial power system,'” IFAC-PapersOnLine, vol. 50, pp. 3368 - 3375, 2017.

[26] H. Rezaie, M. H. Kazemi-Rahbar, B. Vahidi, and H. Rastegar, "Solution of combined economic and emission dispatch problem using a novel chaotic improved harmony search algorithm," Journal of Computational Design and Engineering, vol. 6, no. 3, pp. 447-467, 2018.

[27] S. I. Uskov, D. I. Potemkin, N. Kamboj, P. V. Snytnikov, V. P. Pakharukova, L. V. Enikeeva, I. M. Gubaydullin, and I. Hussainova, "Fibrous aluminabased Ni-MOx (M $=\mathrm{Mg}, \mathrm{Cr}$, Ce) catalysts for propane pre-reforming," Materials Letters, vol. 257, p. 126741, 2019.

[28] S. I. Uskov, L. V. Enikeeva, D. I. Potemkin, V. D. Belyaev, P. V. Snytnikov, I. M. Gubaidullin, V. A. Kirillov, and V. A. Sobyanin, "Kinetics of lowtemperature steam reforming of propane in a methane excess on a Ni-based catalyst," Catalysis in Industry, vol. 9, pp. 104-109, 2017.

[29] S. I. Uskov, D. I. Potemkin, L. V. Enikeeva, P. V. Snytnikov, I. M. Gubaydullin, and V. A. Sobyanin, "Propane pre-reforming into methane-rich gas over Ni catalyst: Experiment and kinetics elucidation via genetic algorithm," Energies, vol. 13, p. 3393, 2020.

[30] I. Gubaydullin, K. Koledina, and L. Sayfullina, "Mathematical modeling of induction period of the olefins hydroalumination reaction by diisobutylaluminiumchloride catalyzed with $\mathrm{Cp}_{2} \mathrm{ZrCl}_{2}$," Engineering Journal, vol. 18, no. 1, pp. 1324, 2014.

[31] L. Enikeeva, I. Gubaydullin, and S. Khursan, "Numerical modeling of intramolecular transformations of ortho, meta-substituted aromatic nitroso oxides," Journal of Physics: Conference Series, vol. 1096, p. 012069, 2018.

[32] A. G. Faskhutdinov, R. I. Faskhutdinova, I. A. Arefyev, and L. V. Enikeeva, "Numerical simulation of the catalytic process of isomerization of pentane-hexane cut," Journal of Physics: Conference Series, vol. 1368, p. 042016, 2019.

[33] C. Koncsag, I. A. Tutun, and C. Safta, "Study of C5/C6 isomerization on $\mathrm{Pt} / \mathrm{H}$-zeolite catalyst in industrial conditions," Ovidius University Annals of Chemistry, vol. 22, pp. 102-106, 2011.

[34] K. F. Koledina and I. M. Gubaidullin, "Kinetics and mechanism of olefin catalytic hydroalumination by organoaluminum compounds," Journal of Physical Chemistry, vol. 90, pp. 914-921, 2016.

[35] K. F. Koledina, I. M. Gubaidullin, S. N. Koledin, A. R. Baiguzina, L. I. Gallyamova, and R. I. Khusnutdinov, "Kinetics and mechanism of the synthesis of benzylbutyl ether in the presence of copper-containing catalysts," Russ. J. Phys. Chem, vol. 93, pp. 2146-2151, 2019.

[36] L. F. Nurislamova, I. M. Gubaydullin, K. F. Koledina, and R. R. Safin, "Kinetic model of the catalytic hydroalumination of olefins with 
organoaluminum compounds," Reaction Kinetics, Mechanisms and Catalysis, vol. 117, pp. 1-14, 2016.

[37] E. Hairer and G. Wanner, Solving Ordinary Differential Equations II: Stiff and Differential-Algebraic Problems. Springer, 2002, Sec. IV.8.

[38] T. Dokeroglu, E. Sevinc, T. Kucukyilmaz, and A. Cosar, "A survey on new generation metaheuristic algorithms," Computers \& Industrial Engineering, vol. 137, p. 106040, 2019.

[39] Z. W. Geem, J. Kim, and G. V. Loganathan, “A new heuristic optimization algorithm: Harmony search," Simulation, vol. 76, no. 2, 2001.
[40] E. Shvareva, L. Enikeeva, and E. Gizzatova, "Harmony search algorithm for chemical kinetics optimization problems," in 2020 International Conference on Information Technology and Nanotechnology (ITNT), Samara, Russia, 2020, pp. 1-4.

[41] A. Yadav, N. Yadav, and J. Kim, "A Comparative study of exploration ability of harmony search algorithms," Advances in Intelligent Systems and Computing, vol. 514, pp. 22-31, 2017.

[42] K. Talaei, A. Rahati, and L. Idoumghar, "A novel harmony search algorithm and its application to data clustering," Applied Soft Computing, vol. 92, p. $106273,2020$.

Leniza V. Enikeeva, photograph and biography not available at the time of publication.

Elena N. Shvareva, photograph and biography not available at the time of publication.

Irek M. Gubaydullin, photograph and biography not available at the time of publication. 